\title{
The Inner Resource: Enabling the Designer within Us All - A Case Study
}

\section{Alastair S. Macdonald School of Design, The Glasgow School of Art, UK}

ABSTRACT The author proposes that within us all is a set of skills, strategies and modes of thinking commonly found in designers that, if recognized, understood and enabled, could potentially be practiced by non-design individuals to assist in improving everyday situations. Inclusive, participative and co-design approaches have tended to include non-design individuals either as part of the consultation process at one end of the 'inclusive' spectrum of design processes, or as an integral member of the design team at the other. The proximity of designers to non-designers in team or workshop situations helps create designerly ways of doing things. This is not only an issue of recognizing and practising these skills and approaches, but also recognizing the conditions under which designing can occur and indeed flourish. Using a research study to explore the tacit use of 'design' skills by spinal cord injuries 
(SCl) survivors as part of a larger project intended to help enhance their own self-reliance and resourcefulness, the author discusses the kinds of skills, thinking and strategies used by $\mathrm{SCl}$ survivors to approach a particular set of problems and asks, if ultimately left to their own devices, could non-design individuals design without designers being present.

KEYWORDS: design skills, resourcefulness, rehabilitation, spinal cord injury

\section{Introduction: The RSA Design and Rehabilitation Project}

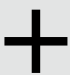

In March 2011 the Royal Society for the Encouragement of the Arts, Manufactures and Commerce (RSA) reported on a three-day Design \& Rehabilitation workshop supported by the Back-Up Trust at the RSA's headquarters in London (Campbell, 2011). The RSA's Design \& Rehabilitation project was 'a design training initiative for people with spinal cord injuries' and proposed that 'design as a discipline, or structured thought process, can address the dramatic loss of confidence and diminished motivation that may result from a sudden physical impairment, and can contribute to independence' (Campbell, 2011). The project was originated and led by Emily Campbell, the then Director of Design at the RSA.

This workshop followed a programme of enquiry which Campbell had pursued within the RSA proposing that 'Design can re-awaken citizens' own resourcefulness.' Her definition of the profession of design was '... common resourcefulness refined by a technical education'. She proposed that 'it is possible to share aspects of this technical education with non-professionals to increase their resourcefulness, and persuade them that they know more than they think about how problems might be solved' (Campbell, 2009). Following her 'innovative experiment', Campbell, supported by the Sylvia Adams Trust, identified three spinal injuries centres in the UK to work with 'the best local universities teaching design' for the next phase of this programme.

This paper describes how Campbell's programme was explored in the collaboration between the School of Design at The Glasgow School of Art (GSA), The Queen Elizabeth National Spinal Injuries Unit (QENSIU) at the Glasgow Southern General Hospital and the University of Strathclyde's Bioengineering Unit in Glasgow (UoS).

\section{The Collaborators}

\section{QENSIU and SCISCI}

QENSIU provides acute care, rehabilitation and lifelong follow up for all patients with a spinal cord injury in Scotland. There are over 100 new injuries per year and an estimated 4,000 patients alive in 
a population of approaching six million. The injury results in the loss of function below the level of the spinal injury with loss of mobility, sensation and bowel, bladder and sexual function. Initial hospitalization is around six months if paralysed from the waist down (paraplegia) and twelve months if paralysed from the neck down (tetraplegia). Research at QENSIU is conducted in the Scottish Centre for Innovation in Spinal Cord Injury (SCISCl), a multidisciplinary alliance of engineers, scientists and clinicians carrying out fundamental and applied clinical research in all disciplines relevant to the treatment and quality of life of people with spinal cord injury.

\section{GSA}

The Design Research for Health and Care (DRHC) group in the School of Design at the GSA undertakes UK cross-council funded research for and within cross-disciplinary healthcare teams relating to, e.g. physical rehabilitation, hospital nutrition, hospital acquired infections and patient pathway modelling using a rich mixed methods and participative approach, where 'design' methods are integrated into the overall project research methodologies to explore innovative approaches to the design, redesign and delivery of healthcare services.

\section{UoS}

Bioengineering at UoS operates at the interface between engineering, medicine and the life and physical sciences. Based on the application of advances in science, engineering and technology, bioengineering takes a multidisciplinary approach to problem solving. A major focus is to improve the quality of life of people with medical conditions that restrict independent living and integration with the community.

\section{Understanding SCI and the Rehabilitation Pathway}

For the author, it was essential to understand $\mathrm{SCl}$, the problems and issues facing $\mathrm{SCl}$ survivors and their rehabilitation pathway through QENSIU. This was facilitated by an extensive and ongoing dialogue with QENSIU which provided, for background, journal papers exploring particularly problematic issues, DVDs explaining the $\mathrm{SCl}$ condition and promoting support services, a copy of their SCl Patient Pathway (SCIPP) and other materials.

\section{Issues}

$\mathrm{SCl}$ and its impact is complex and it is not the intention nor is it within the capability of this author to rehearse a discussion of the extensive literature regarding $\mathrm{SCl}$, the resulting devastation of $\mathrm{SCl}$ and different clinical approaches to rehabilitation, but instead to highlight a number of particularly resonant issues and questions arising from discussions with QENSIU consultants and from background reading of key literature pertinent to the project's purpose. 
The SCIPP is largely concerned with defining the pathway within QENSIU (i.e. within the rehabilitation unit) although this also contains a phase for a return to the community. QENSIU extends lifelong follow-up to survivors. One of the issues identified by QENSIU and in the literature is the difficulty in adjusting to post-discharge life following a SCl with approximately one year post-discharge being the most problematic period. Dickson et al (2011a, b) focus on survivors' and their carers' lived experiences of $\mathrm{SCl}$, and survivors' difficulties in adjusting to home and community life following discharge. In contrast to the busy, supportive community of individuals with the same broad SCI conditions found in QENSIU, survivors returning to the community experience, e.g. a 'loss of camaraderie', 'lack of post-discharge care' and 'other people's [negative] reactions to SCl' (Dickson et al, 2011b). They can also have 'difficulties in accepting the new, disabled self' and it can take five to seven years to adapt and reach 'stability'. Adaptation is required at three levels, at the: i) individual (a strong desire for independence for successful adjustment); ii) social (reintegration as an active member of the community and enhances self-worth and esteem); and iii) environmental (accessibility and the public's attunement in interactions with disabled individuals) levels (Dickson et al, 2011b). Noticeably, the SCI 'patient voice' is largely absent from the literature, revealed in only a few studies, such as in Dickson et al (2011a, b).

Given the complexity of the QENSIU rehabilitation pathway, the author developed simplified patient pathway models from issues raised in the literature and through discussion to help model key issues facing an individual. This threw into stark contrast the difference between life within QENSIU and return to the community and highlighted two key transitions: i) adjustment from life before injury to that in the rehab unit; and ii) adjustment to life in the community and home after discharge from the rehab unit. These constitute two episodes of 'biographical disruption' which can involve, e.g. 'grieving for one's past life' with trepidation about one's future, 're-inventing and renegotiating one's self and identity' (Bury, 1982). Another issue has been the shift towards the legitimacy of the 'lay' voice and 'how people use narratives to give meaning and voice to their suffering over time' (Lawton, 2009). Having coped with the first disruption following SCl and adjusted to the community and life within QENSIU (transition 1), SCl survivors are then faced with another phase of disruption and adjustment on their return to the community (transition 2). Although simplified for the purposes of illustrating the issues, the contrasts are stark (Figure 1).

The Goal Planning Checklist (Figure 2) is used to help staff and patients plan the complex management of many different functions simultaneously, e.g. bowel, bladder, skin and sexual functions. This checklist, a detailed 18-page document, reveals just how complex and 'wicked' a problem the simultaneous functional management of the many aspects of $\mathrm{SCl}$ is. 


\begin{tabular}{|c|c|c|c|c|}
\hline \multicolumn{5}{|c|}{ Future Life } \\
\hline $\begin{array}{l}\text { Previous } \\
\text { Life }\end{array}$ & Incident & Acute & $\begin{array}{l}\text { Rehab } \\
\text { Unit }\end{array}$ & Community / Home \\
\hline \multicolumn{4}{|c|}{ Adaptation / adjustment to life in the unit } & $\begin{array}{l}\text { Adaptation / adjustment to life at home (perhaps via } \\
\text { nursing home }\end{array}$ \\
\hline \multicolumn{4}{|c|}{$\begin{array}{r}\begin{array}{r}\text { Growing camaraderie with others in the unit (sense of } \\
\text { belonging) }\end{array} \\
\end{array}$} & Sense of Isolation \\
\hline \multicolumn{4}{|c|}{$\begin{array}{r}\text { Increasing sense of being 'normal' within a disabled } \\
\text { community }\end{array}$} & $\begin{array}{l}\text { 'Abnormal' within an able-bodied community: } \\
\text { stigmatising reactions }\end{array}$ \\
\hline \multicolumn{4}{|c|}{ Support for improving physical condition } & (Lack of) support / physical de-conditioning \\
\hline \multicolumn{4}{|c|}{ Growing feeling of safety and security } & Feeling of being exposed / isolated \\
\hline \multicolumn{4}{|c|}{ Busy environment } & Quiet environment \\
\hline \multicolumn{5}{|c|}{$\begin{array}{l}\text { Transition / biographical disruption 1: } \\
\text { previous life to rehabilitation unit } \\
\text { Grieving for one's past life and trepidation about one's } \\
\text { future. Reinventing and renegotiating one's self and } \\
\text { identity. Learning to become a member of the QENSIU } \\
\text { community. }\end{array}$} \\
\hline & & & \multicolumn{2}{|c|}{$\begin{array}{l}\text { Transition / biographical disruption 2: } \\
\text { rehabilitation unit to community and home life } \\
\text { Having coped with and adapted to the community and life within } \\
\text { QENSIU, SCI survivors are faced with another stage of adjustment } \\
\text { without the peer and professional support found in QENSIU }\end{array}$} \\
\hline
\end{tabular}

\section{Figure 1}

$\mathrm{SCl}$ survivor transitions.

\section{Acute Services Division}

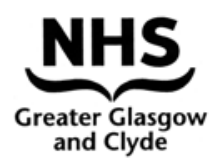

Queen Elizabeth National Spinal Injuries Unit

\section{Goal Planning Checklist}

Patient details

\begin{tabular}{|l|l|l|}
\hline Name: & D.O.B & Unit No: \\
\hline Level of Injury: & ASIA Impairment Scalle: \\
\hline Key Worker: & Consultant: \\
\hline Named Nurse: & Ptysiotherapist: \\
\hline Occupational Therapist: & Pychologist: \\
\hline Social Worker: & Date of Allocation of Key Worker: \\
\hline Date of 1st Administration: & - Needs Assessment: \\
\hline Date of 2nd Administration: & - Pre-Discharge Assessment: \\
\hline Functional independence measurement on admission - score: \\
\hline Functional independence measurement at first goal planning - score: \\
\hline Functional independence measurement at pre-discharge assessment - score: \\
\hline
\end{tabular}

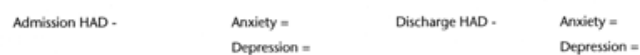

- If greater than 8 please refer to pschychologist"

This is a checklist of things that you will need to learn about Spinal Cord Injury. During your stay here, you will be taught lots of things. This checklist helps us:

A - to assess and identify what you need to know

B - what you are able to do

C - what you still have to learn or achieve

I, your Key Worker, will complete the checklist with you. Remember, there are no right or wrong answers. This is simply to help us work out what your Rehabilitation programme should consist of. We call it Goal Planning.

\section{Figure 2}

Goal Planning Checklist. Courtesy of the National Spinal Injuries Unit. 
Overall, the rehab pathway and the management of functions both appeared complex, involving many specialist disciplines working individually and in concert to help support SCl survivors to manage all these separate functions. Every $\mathrm{SCl}$ is different as is each $\mathrm{SCl}$ survivor and their accompanying capabilities and attitudes, so another challenge for QENSIU is how, throughout the rehab pathway, to enable bespoke therapeutic and rehabilitative approaches in response to individual needs, situations and priorities.

\section{QENSIU and Models of Design}

The medical model of disability and ageing implies that people are disabled as a consequence of their condition, and seeks to either remedy or correct the impairment through medication, rehabilitation and surgery etc., or offers adaptive aids and equipment as a physical remedy. In this model 'the impairment is the problem'. In contrast, the social model sees people as disabled or enabled by the social context in which they function and proposes that changes in the social context or environment can remove or alleviate disability. In this model 'the structures within society are the problem'. While not wishing to simplistically assign the one model of disability or the other to one party or another, these two models perhaps - of necessity - coexist and are useful to hold in mind here. In QENSIU, design - in the 'design engineering' sense - has been very successful in sourcing or developing assistive rehabilitation technologies and equipment. In this model, design functions as an 'external' agent assisting or compensating for an individual's functional disability. Design in Campbell's sense, i.e. functioning as an 'internal' agent to help develop self-reliance and resourcefulness, had not previously been explored.

Throughout the initial phase of this work, the following questions persisted: i) could 'design' approaches possibly be used to complement current clinical approaches and to address some of the management issues that face $\mathrm{SCl}$ survivors, i.e. not in terms of the clinical management of the functions cited above, but in, e.g. addressing problems of daily living and returning-to-the-community issues, and identifying how environments and services could be better designed to support SCl needs?; ii) if so, how and where?; and iii) could different kinds of design approaches and methods be used for different kinds of problems or issues, or at different stages when unpacking or addressing a complex problem?

\section{Glasgow's Approach}

The Glasgow project provided the opportunity to evolve the RSA's experimental programme into its own and proceeded with three areas of enquiry:

1. People are naturally resourceful and can (potentially) design. In many situations, e.g. do-it-yourself (DIY), gardening and setting 
up neighbourhood committees, or simply planning activities of daily living, individuals can be resourceful and so non-designers might have a set (or a subset) of problem-solving and design 'skills' to a greater or lesser extent than designers but not be aware of these or how to deploy these in as structured and practical a way.

2. Design literatures support the idea that designers appear to have a distinctive and (variously) definable set of skills, methods, processes, types of thinking and approaches that they use when designing, when tackling problems and working towards solutions.

3. Designers are able to explicitly differentiate and articulate the use of, rather than solely tacitly use, different skills and methods and may be able to help non-designers (in this case SCl survivors) recognize and apply these to increase their resourcefulness, and heighten their awareness that they know more than they think about how problems might be solved.

From this stage arose a set of research questions: 1) what is the skill set of designers?; 2) what are the innate skills of SCl survivors?; 3) what is the match between designers' skills and SCl survivors' skills?; 4) could, and how could, SCl survivors' awareness of innate 'design' skills be developed to enhance their resourcefulness and self-reliance in tackling the daily life challenges of living with SCl?; and 5) what are the conditions under which the activity and self-practice of designing could be encouraged i.e. without the designer's presence?

\section{Design and Designing}

Due to the recent and rapid growth of activity in the 'service' and 'inclusive' design fields, a resource of methods, tools and case studies is now available to designers. Within healthcare, design-led participatory approaches have been piloted to help the NHS 'think differently' about how healthcare services could be delivered. For example, Cottam and Leadbeater (2004) explored innovative approaches to diabetes management. Bate and Robert (2007) provided a userexperience-centred response to the NHS system reform programme set out in the Department of Health's (2005) patient-led plan. The $\mathrm{NHS}$ Institute for Innovation and Improvement has been exploring the use of designers in the redesign of healthcare services (Design Council, 2008), and Pickles et al (2008) discussed practical methods of working with patients to redesign services. Tassi (2009) provides a tool summarizing useful methods, as do Stickdorn and Schneider (2010), who, along with Meroni and Sangiorgi (2011), provide a number of interesting case studies. A number of service design consultancies (Engine, 2012; Thinkpublic, 2012) and research centres also make their resources available online. 
However, despite the proliferation and general availability of these approaches, methods and tools, to proceed it was important for the author to have a clearer understanding of what is meant by 'designing', and 'design approaches' to describe the kinds of desirable (i.e. within this context) attributes that designers might possess and to understand if these are innate but unconscious or unpractised in SCl survivors.

In research conducted for the Design Council, 'Design skills for work', Kimbell and Miller (1999) explored the identification and definition of design skills in the context of their teachability and their potential application outside the field of design to the wider world of work. From their research, Kimbell and Miller derived a framework for transferable design skills where they sought to determine the range of skills which tended to be used by designers during designing, including those skills which might be regarded as particularly 'designerly'. They discussed higher order and more prosaic skills, both of which are not particularly distinctive to designing as these are also found in other fields, but also a third, middle, level which they claimed distinguishes the design experience, the procedures and operational strategies (i.e. the way designers do what they do, their designerly modes of operation) that provide design students with a different kind of experience from other forms of training, and which provide them with a distinct array of skills for employment. These they categorized as follows.

Higher order (intentions/purposes): plan/order; generate/create; investigate/find out; evaluate/judge; communicate/present. Operational strategies (making thinking explicit): unpack wicked tasks; iterative thinking; playing with reality; optimizing values; modelling futures; managing complexity and uncertainty; optimized decision-making; collaborating (creative brainstorming); collaborating (evaluating/planning); research - seeking knowledge. Functional (skills): talking; writing; calculating; drawing; making.

In the ongoing work of a separate and more recent author, Kimbell $(2009,2011)$ finds that the term 'design thinking' is currently confused and proposes 'an alternative way of conceiving of design activity, without privileging the work done by designers, by attending to the practices of others involved in constituting design outcomes' (Kimbell, 2009). She categorizes key themes and contradictions that appear across the literatures about the nature of design activity or design thinking, across the categories of: i) a cognitive style; ii) a general theory of design; and/or iii) an organizational resource (Kimbell, 2011). In her work, she moves towards theories of 'design practice' as distinct from the more problematic term - for her - of 'design thinking'. Her contribution, she states, 'is to articulate the main problems with the term [design thinking] and suggest a new way of conceiving of design activity that links what designers do with what stakeholders such as end-users and others do'. She discusses 'the importance of putting end-users and stakeholders at 
the heart of design' which is relevant to the discussion of inclusive design and the question of with whom the privilege of designing is actually situated, i.e. 'it becomes important to acknowledge the part that end-users and other stakeholders play in constituting the effects of design through practice ... end-users and stakeholders are co-designers as they engage with objects in their practices ...' and regards design as ' . . . a distributed social accomplishment', 'not just as the work of design professionals but also of the ... end-users and other stakeholders whose practices constitute design and its objects in different ways'.

\section{The QENSIU Design Seminar}

Just as the author was required to understand $\mathrm{SCl}$, the problems and issues facing $\mathrm{SCl}$ survivors and their rehabilitation pathway through QENSIU, reciprocally it was desirable that QENSIU staff and SCI survivors developed an understanding of the potential value and application of design methods and approaches to some of the issues they faced.

To open up the wider discussion about the possible exploration of the use of design practices, approaches and methods in QENSIU, the author identified a number of exemplars of how these have been used within healthcare and rehabilitation research settings which might be appropriate to the kinds of issues identified in the SCl literature and through prior discussions with QENSIU, and developed a half-day seminar programme for QENSIU staff and SCI survivors. Examples of design methods and approaches provided during the seminar were by no means intended to be exhaustive or definitive but essentially illustrative of the many methods and approaches increasingly in common use in design. These were selected to respond to a number of themes and issues identified in the first stage and to help open up discussion of new modes or ways of viewing and exploring issues to complement those used currently in the predominantly 'medical/clinical' world view. The seminar was structured through the following series of short presentations of examples each followed by a brief opportunity for feedback and discussion.

\section{Patient-centred experiences of the pathway}

The literature revealed the issue of a paucity of information on 'patient-voiced' issues. Visual storyboarding methods using 'vignettes' have been used to, e.g. provide all those concerned with preparing, supplying and delivering patient meals to vulnerable older adults in hospitals the means to identify and raise patient-centred issues at different stages of the mealtime event which, separately and collectively, potentially lead to the chronic malnutrition problems currently experienced in the UK's NHS (Macdonald et al, 2012). This method, together with the development of 'personas', helps build pictures of patient as well as healthcare staff's (i.e. the various stakeholders') experiences of the service. 


\section{Scenario-building and narrative techniques}

One issue which emerged from Dickson et al (2011b) was in adapting to home life post-discharge, a stark contrast to life in the rehab unit. There appeared to be potential for using scenario-building and narrative techniques as either a way of anticipating, whilst still in QENSIU, what some of the issues might be post-discharge before this stage occurs or how improvements could be made to the status quo once back in the community. Again examples were provided from the author's own portfolio (Macdonald et al, 2012).

\section{What if ... ?}

One issue highlighted in discussions with QENSIU is that paramedical staff can find it difficult to accept new procedures, habituated as they can be come to the service status quo. Indeed staff inertia is often an impediment to service redesign and improvement. Design methods and practices have been used to explore how services could be designed and delivered differently using 'what if ...?' techniques, e.g. by showing how other types of service companies (e.g. completely unrelated to healthcare), could potentially deliver improved services because of their customer-centred approaches and service principles (Macdonald et al, 2012).

\section{Image and self-image}

Image and self-image for SCl survivors was an important issue as revealed in DVDs for SCl support services that had been supplied to the author. Although participation in Paralympic-type activities allows the assimilation of SCl survivors into the competitive sports mainstream, and although the attainment of physical strength and development of a determined mindset are perhaps necessary attributes for SCl survivors, the author wondered if there was room to explore other 'images of self' if one was not predisposed to the 'athletic' image. Another dimension to this is how one could approach the issue of portraying people with $\mathrm{SCl}$ disabilities to the wider community to address both the 'social stigma' issue identified in Dickson et al (2011b) and also a point raised by QENSIU: 'Our interest in the design process is to define a core generic pathway that can be individually tailored'. Examples of how image and identity is being used to explore gendered and ageing identities were shown, e.g. Warren et al (2012).

\section{The QENSIU Workshop}

If the skills of designers, their practices or ways of doing things are already on the way to being described and categorized (Kimbell and Miller, 1999; Kimbell 2009, 2011) and with reference to the research questions raised previously, the objective of the next phase of the Glasgow project, a workshop with SCl survivors, was designed to start to explore one of the questions raised previously, i.e. 'what are the innate (designing) skills of SCl survivors?' 
Following the seminar, a number of possible themes and ideas for a workshop were explored but one aspect of daily life identified by QENSIU which appeared to be particularly problematic was the very practical difficulties posed for SCl survivors shopping for clothing. Initially this was perceived from the viewpoint of the practicalities of donning and wearing clothing and its functional performance (i.e. fastenings, technical performance of materials for, e.g. prevention of pressure sores, moisture control etc.). Indeed, such a collaboration had taken place previously between QENSIU and a company resulting in the design of clothing for SCl survivors to meet these kinds of functional requirements (i.e. design as an 'external' agent). However, in contrast, the 'shopping journey' as a total user experience was subsequently developed as a theme to explore a) the range of complex and interrelated issues for SCl survivors and b) their skills at tackling various problems and issues arising from this; this shopping activity was chosen as it encompassed a number of stages and a degree of complexity, reflecting many daily life situations and how design could potentially be used as an 'internal' agent.

The workshop developed on this theme was held in the Step Down Unit at QENSIU. It comprised three separate but related activities and an evaluation and feedback session. SCl survivors (three outpatients in wheelchairs, one in-patient in bed, with a further wheelchair outpatient joining later for Activity 3) completed the three activities prior to staff joining the discussion session to allow SCl survivors to speak and act freely. A number of QENSIU clinical, ward staff and therapists joined the workshop after Activity 3 to witness the results and participant feedback.

In design workshops, it is perhaps habitual for design facilitators to help 'lead' participants towards ideas and potential solutions. For such participants, novelty of 'design' approach or activity can create an interesting and often unfamiliar kind of experience, compared to more usual forms of 'consultation', and here an issue is whose ideas are being considered and developed and whose skills are being revealed (i.e. to what extent are these the designers' (through their facilitation role), or the participants', or the degree of a mix of the two?). This is an important issue for this project as, if SCl survivors are to use design approaches, we need to have an understanding of what skills they already possess and if they could ultimately use these without the need for trained designers to be present. Here, because it was important to understand what the SCl participants' own innate skills were, careful briefing of the facilitators was crucial; they were instructed not to 'lead' but to 'enable' the participants. SCl participants were paired and two facilitators were assigned to each SCl pair to capture comments (sticky notes) and issues and ideas (sketch visualized).

\section{Activity 1: Personal shopper}

Feedback from the SCl survivors during discussion after each section in the afore-mentioned seminar was typified by 'autobiographic' 
anecdotes and narratives, i.e. an individual's recounting of his/her own history of their injuries and attempts to come to terms and adjust to their new lives with $\mathrm{SCl}$. As one key ability, not unique to but certainly well-exercised within user-centred design and codesign approaches, is to be able to think of another's needs, the first workshop activity used the scenario of role-playing the 'personal shopper' for their workshop partner with the brief to identify clothing for a special occasion, where looking good and a projection of their partner's individual preferences and personality were important (Figures 3 and 4). The objective was to break through the 'tracksuit bottom' syndrome (i.e. types of clothing which tend to be easiest worn at the expense of style or self-image) to see if SCl survivors could consider and project others', as distinct from their own, needs. At the end of this activity each partner in the pair briefly described the other's personality and preferences for clothing for the occasion. The interesting observation emerging from this activity was that, in contrast to the 'autobiographical' mode used when discussing their own personal experiences and difficulties in the previous seminar, $\mathrm{SCl}$ survivors could begin to think and act from the perspective of another person's needs. Interestingly, this type of discussion where the SCI survivor had become a 'carer', as distinct from 'one who was cared for', was not one that QENSIU staff were used to hearing, the autobiographical account being the norm. Whether they would have tended to do this of their own volition without a facilitated activity is another question discussed below.

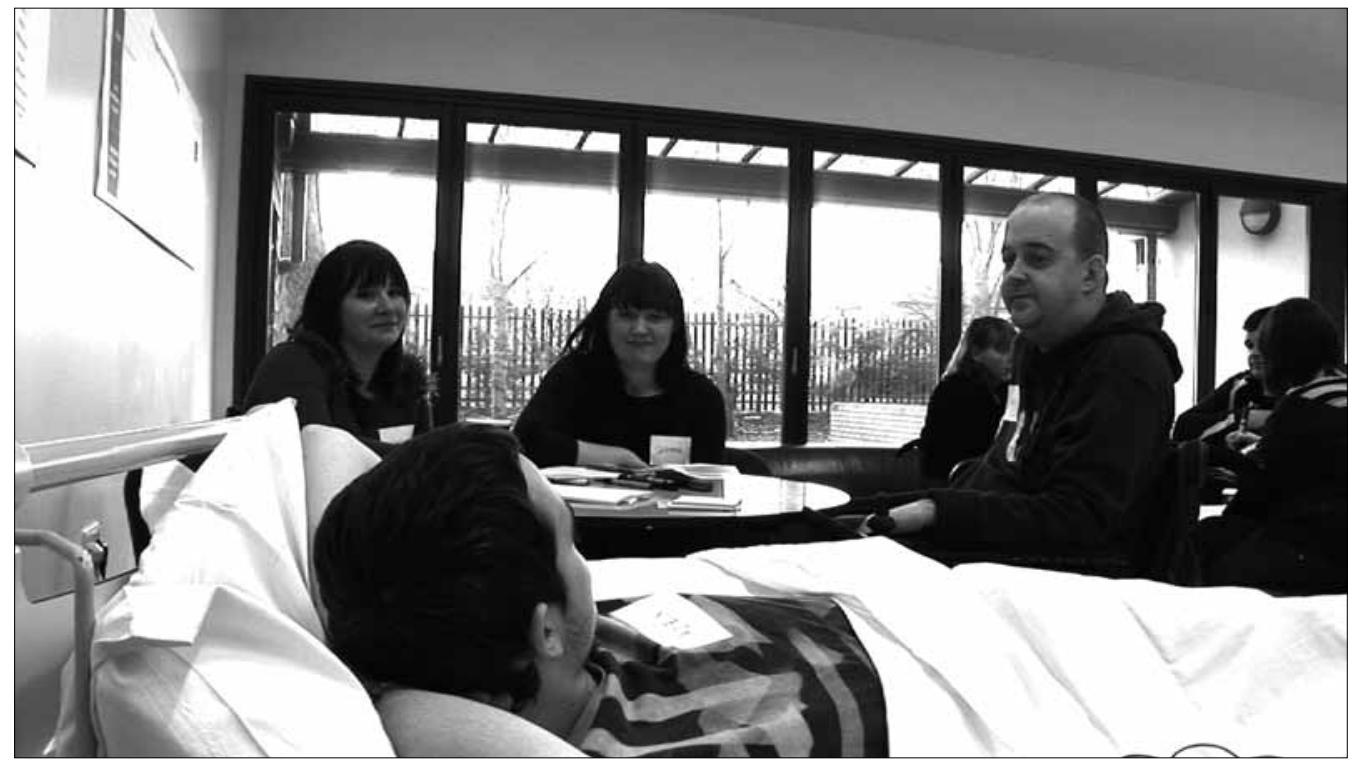

Figure 3

Activity 1: 'Personal shopper' discussions. Image @ C Claire Levy 2012. 


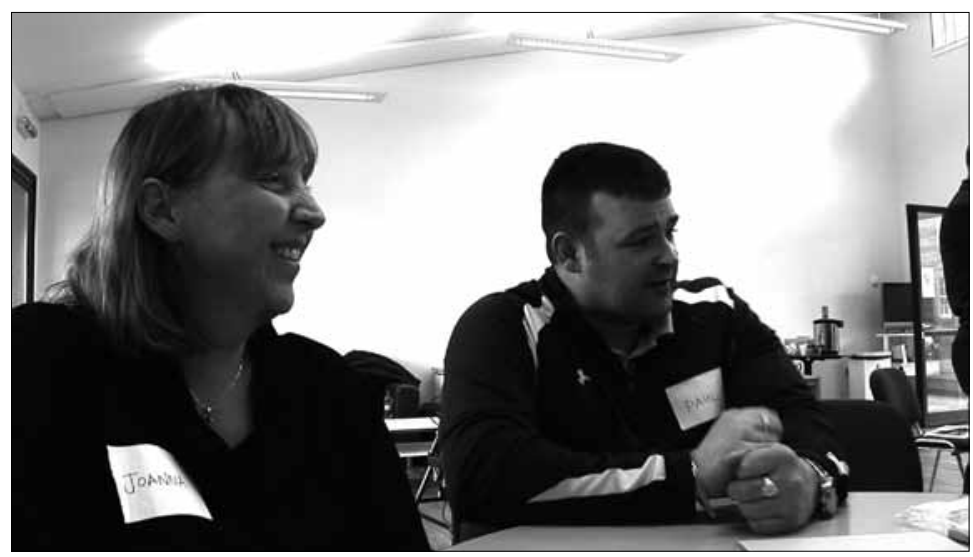

\section{Activity 2: The shopping 'status quo'}

For purchasing clothing for their special occasions the second activity explored the 'shopping journey' to understand how well SCl survivors were able to identify and define problems encountered during that experience. Such a shopping journey would normally involve travelling to and arriving at a store or shopping centre by some form of transport, finding one's way to the chosen department, wandering around, looking at and handling clothes and fabrics, and trying on clothing to assess fit, look and feel and so on as part of the experience and decision-making process. Although compliant with disability accessibility acts, many stores have limited accessibility and facilities for disabled and SCl people, leading to people being to a greater or lesser extent - both physically and socially limited or excluded from the full range of their previous (i.e. pre-SCl) shopping experiences perhaps resulting in a preference to shop using mail order and specialist suppliers.

For the purposes of the workshop, the shopping journey was deconstructed into a series of distinct stages or episodes and after being prompted by visual cues for each stage, $\mathrm{SCl}$ survivors were asked to think about and rapidly describe their own shopping experiences and to identify problems and issues they had with current store-based (as distinct from online) experiences of shopping for clothes, describing what happens, how this made them feel and what they thought needed to be addressed. At the end of this session one of the patient representatives from each group was again asked to make a quick two-minute presentation of key issues identified.

To facilitate this activity, a large format printed matrix 'The shopping experience: the status quo' (Figure 5) was provided onto which their facilitated comments and issues were placed (Figure 6). This resulted in a rudimentary 'experience' or 'shopping-journey' map creating a visually annotated critique of the status quo, identifying through the process some key issues or problems for potential

\section{Figure 4}

Activity 1: 'Personal shopper' discussions. Image () Claire Levy 2012. 


\begin{tabular}{|c|l|l|l|l|l|l|l|}
\hline stage \\
\hline $\begin{array}{c}\text { pany } \\
\text { problems/ } \\
\text { issues? }\end{array}$
\end{tabular}

\begin{tabular}{|l|l|l|l|l|l|l|l|}
\hline $\begin{array}{c}\text { the ideal } \\
\text { shopping } \\
\text { experience }\end{array}$ & & & & & & & \\
\end{tabular}

\section{Figure 5}

The printed matrix which was used to capture SCl survivors' comments on 'the shopping experience: the status quo'. improvement of the shopping experience. This revealed a range of tangible interaction and service 'touch-point' issues such as parking, clearly seeing and feeling garments, seeking assistance and storing bags of shopping as well as more intangible (de)motivating, and emotionally frustrating issues, such as constantly having to ask for assistance, and 'feeling like you're nagging' assistants.

Results indicated that SCl survivors were well able to identify and specify problems, another declared design attribute. However, in order to facilitate this, the shopping journey had to be preconceived and deconstructed by the designers, not only into the distinct phases, but also structured to allow for the capture of the more emotive issues as well as practical difficulties relating to the status quo

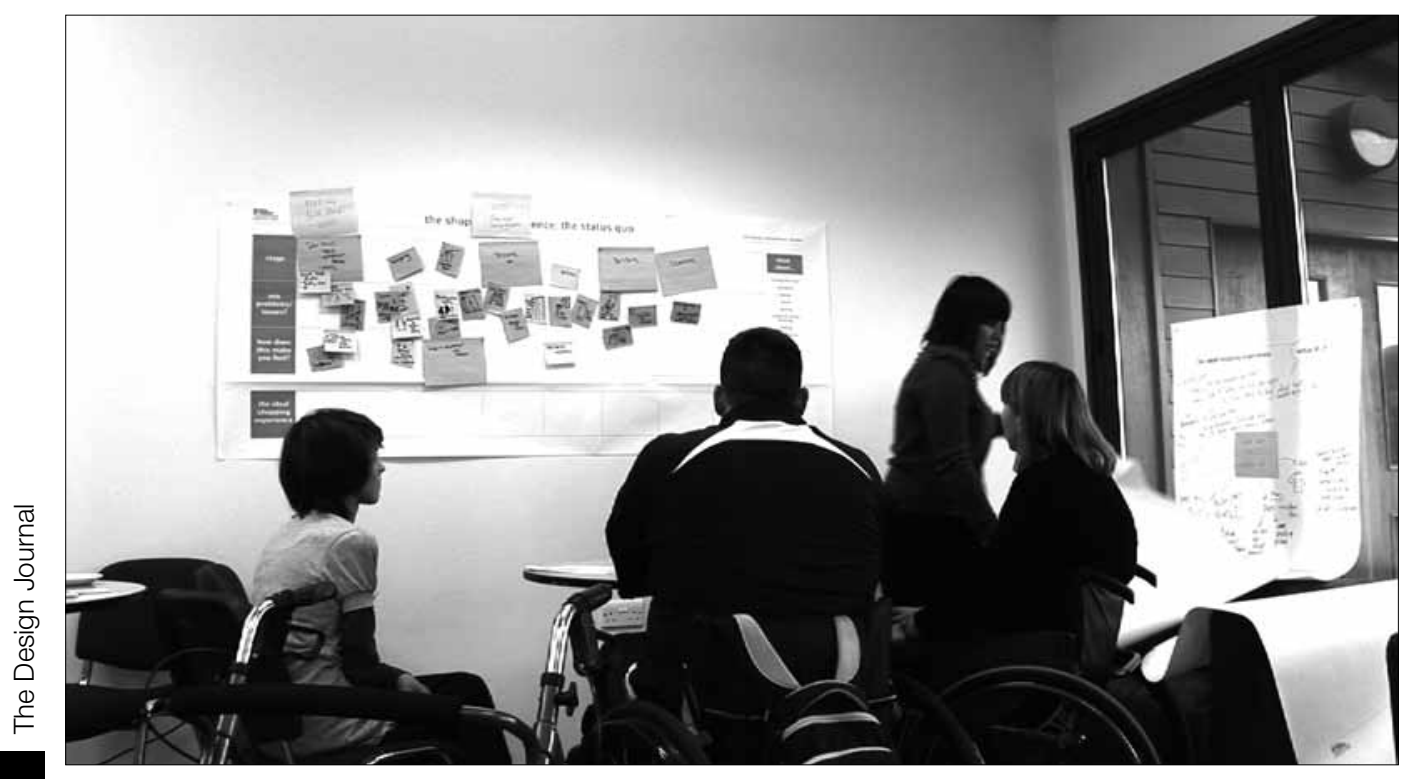


shopping experience. The envisioning of the participants' comments and issues by the facilitators no doubt helped participants begin to specify and 'see' the issues in ways that they would not have been done so before. So although these problem-identification skills are apparent in the SCl survivors, the designerly approach of unpacking the issues enabled these to be practiced.

\section{Activity 3: What if ...?}

Having discussed the problems and issues with the shopping status quo and identified a number of key issues and problems, SCl survivors were given the opportunity to imagine and design improved 'store-based' shopping experiences using as their starting point the problematic issues they had identified in Activity 2. Activity 3 used the kinds of 'what if ...?' approaches familiarly used by designers during brainstorming- and workshop-type activities. Facilitators provoked discussion (without adding ideas of their own), recording and helping visualize ideas volunteered by SCl survivors. Again at the activity's end participants were asked to quickly summarize how their ideas might lead to an improved shopping experience. Many ideas, such as a shopping centre collection service for wheelchair shoppers, centralizing and storing all bags bought in different shops until ready to leave the car park, were generated.

Initially, this was the most difficult of the three activities for the SCl survivors to engage with. One interpretation of this might be that the status quo was so problematic that they had become habituated to this to the extent that it was difficult for them to imagine how the experience could be improved and also perhaps because the idea of exploring improved or 'ideal' scenarios was not one familiar to them. However, with appropriate encouragement, some interesting ideas, envisioned by the facilitators (Figures 7 and 8), began to emerge demonstrating that once enabled the $\mathrm{SCl}$ survivors also innately possessed the kinds of speculative and imaginative skills which designers are fond of citing as part of their own skill set. This activity created a bank of ideas that could potentially be prototyped, tested and refined.

\section{Feedback session}

Before participants were invited to provide verbal feedback on the value of the morning's activities, they were asked to individually reflect on and, using a simple matrix, indicate which different kinds of thinking, strategies and skills they thought they had used in each of the three activities, perhaps using some in all three activities and others in only one, or none in any, or some that were not listed. It was stressed that there were no correct answers here, only their own perceptions of what they thought they had used. The matrix of types of thinking, strategies and skills was derived from Kimbell et al (1999). Participants were given about 15 minutes to consider and complete this but the results were not as anticipated; it was anticipated that 


\section{Figure 7}

Activity 3: Examples of 'what if ... ?' SCl survivors' ideas captured and visualized by facilitators. Image (C) Claire Levy 2012.

\section{Figure 8}

Activity 3: Examples of 'what if ... ?' SCl survivors' ideas captured and visualized by facilitators. Image (C) Claire Levy 2012.
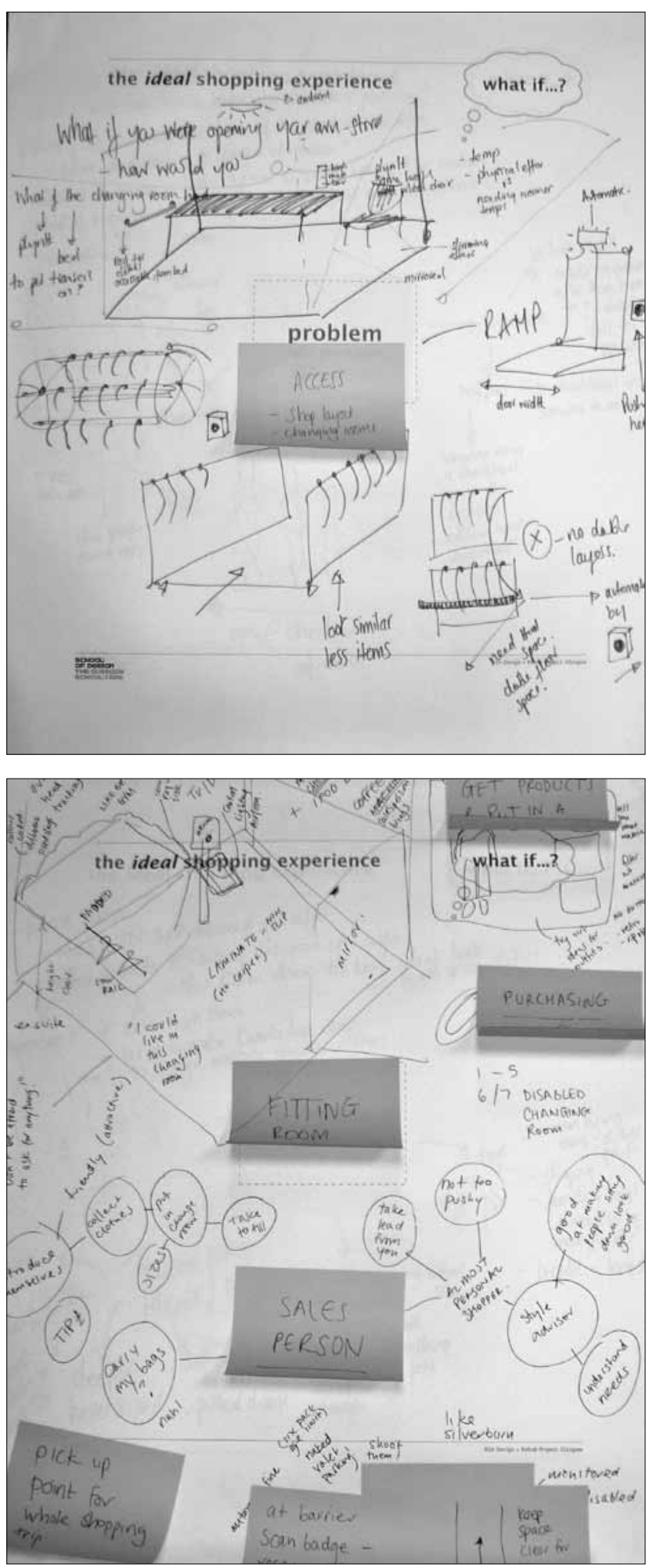


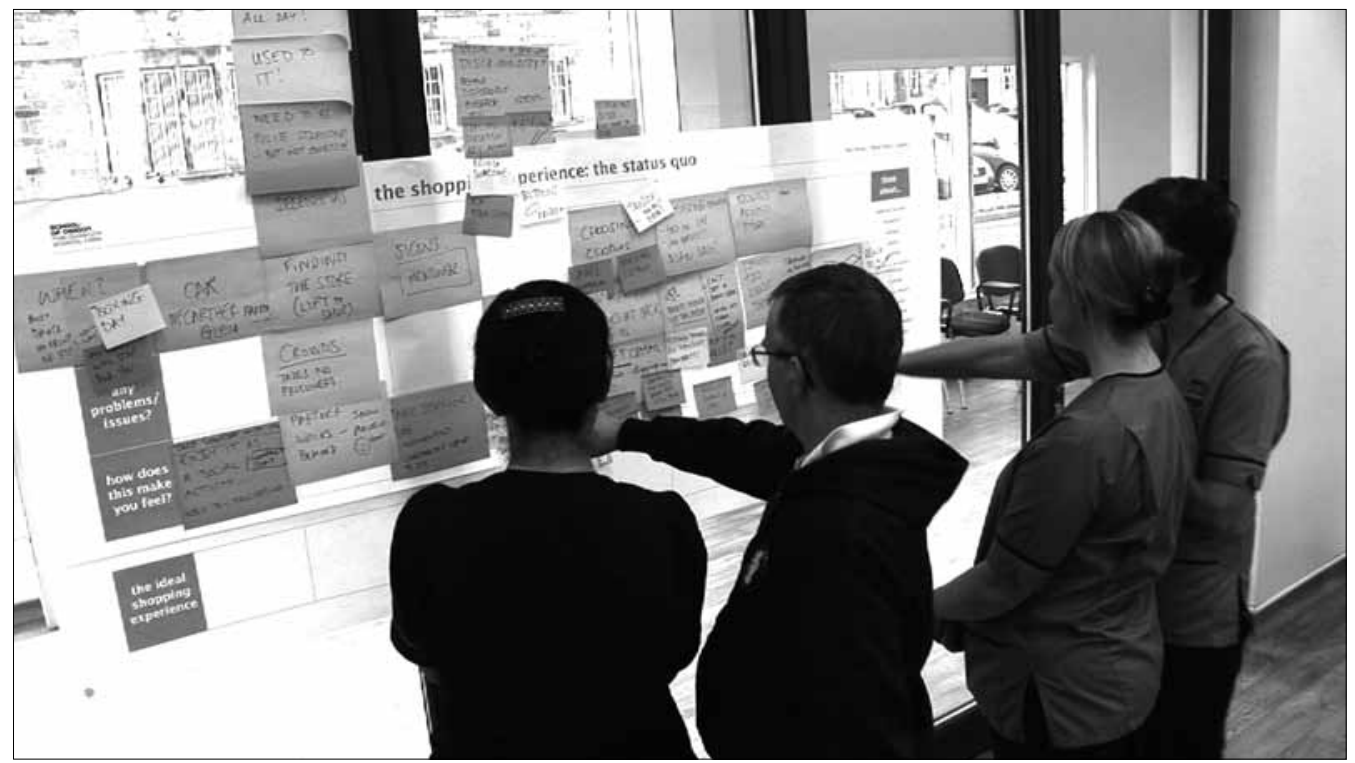

there would be distinctive clustering of different sets of skills for each of the three different kinds of activities. Presented with the 'tick box' matrix, participants' tendency may have been to tick all available boxes. This suggests the method for obtaining feedback was flawed and that semi-structured interviews might have been more accurate in revealing which combinations of skills were used in which kinds of activities. Interestingly, during this session, therapists and ward staff viewing the outcomes of the SCl participants' issues and ideas recorded on the workshop activity boards (Figure 9) volunteered that they had not heard SCl survivors discuss these issues in this manner or were not aware that they had had particular kinds of difficulties.

\section{Reflection on the Outcomes from the Workshop}

During the workshop only some of the full spectrum of thinking modes, strategies and skills that designers utilize during the process of designing were explored, i.e. none of the ideas were prototyped, tested or refined. However, the author has explored these later stages in the design process, also involving non-designers in previous work (Macdonald et al, 2012) and found similar results; under certain conditions non-designers are capable and sometimes adept at, e.g. prototyping experiences and products. However in the three activities in this workshop the SCI survivors demonstrated that, to a greater or lesser extent, they could clearly: i) think of others' needs; ii) identify and detail problems with current service provision (i.e. the shopping experience); and iii) imagine improved scenarios/designs, thereby revealing that SCl survivors possess at least some of the same skills as designers, although perhaps not used so intuitively, consciously or as in as practised or structured a manner as designers.

Figure 9

QENSIU staff discussing $\mathrm{SCl}$ survivors' issues and comments from Activity 2. Image (C) Claire Levy 2012. 
Just as SCl survivors and staff use the previously mentioned Goal Planning Checklist to help manage the complexity of many different functions simultaneously, would an equivalent 'toolkit', which provides and describes different 'design' skills, modes and approaches, together with some exemplar case studies, help SCl survivors unpack and approach some of the 'wicked problems' that face them in daily living? An early emerging question in the author's mind was whether a taxonomy of such design approaches and methods together with appropriate and exemplary case study material would be useful for $\mathrm{SCl}$ survivors? This is not an original idea and resources have previously been created by e.g. IDEO (2009) to assist the transfer of design methods to others, in IDEO's case for use in tackling design issues in developing countries.

\section{Discussion}

Although a 'design toolkit' resource might be useful and worth exploring, would this be sufficient in itself? In workshops such as these, while we can demonstrate that 'designing' occurs using recognizable and categorized sets of skills and approaches, it is not just a matter of $\mathrm{SCl}$ survivors developing or acquiring the designer's particular bag of skills.

Throughout this enquiry, questions emerged such as: 1) how much exposure might $\mathrm{SCl}$ survivors require through design activities for them to begin to develop sufficient skills without having to undertake the normal kind of training a designer would undertake?; 2) how enduring would these learnt skills be i.e. once the immediacy and novelty of workshop-type experiences had receded, for how long could they continue to apply these (i.e. would any effect be limited)?; and 3) and at what point could/do SCl survivors begin to autonomously address some of the 'wicked problems' of daily living they face, through the practice and application of design approaches?

We have no data to answer the above questions; a longitudinal study of the durable impact of the initial RSA pilot has not been made, and indeed it was only intended as an exploratory experiment. One of the challenges of this project is not only understanding if non-designers can 'design' as such and to what extent, but under what conditions can designing be best fostered and flourish? If selfreliance and resourcefulness are to be developed by SCl survivors through designing-type activities (i.e. the RSA's agenda) either whilst within a SCI unit such as QENSIU or post-discharge, the challenge would not only be to develop within the individual designerly skills and methods per se but also to create the requisite conditions or environments for these to be applied or practised either within a unit (in this case QENSIU) which has (understandably) a predominantly medical/clinical ethos with a certain kind of professional-survivor hierarchy, or in the relatively more isolated and less supported environment of the community or home. Interestingly, according to QENSIU, the nature of the SCI relationship with QENSIU evolves 
during the initial post-discharge phase; often there has to be a period of separation before the patient develops a more mature and less dependent relationship. Obviously, the workshop-type scenarios such as those held in the original RSA pilot or QENSIU's Step Down Unit offer models, albeit one-off, for ways of engaging SCl survivors which are different to the medical/clinical practices normally prevailing in a rehab unit and which also provide a level of resourcing which $\mathrm{SCl}$ survivors - and indeed SCl units - cannot normally access.

\section{Conclusion}

The preceding discussion cannot begin to acknowledge the extent of the devastation caused by a SCl or the complexity of the challenge the RSA thesis presents. The post-discharge phase is a dynamically evolving one. According to QENSIU, initially patients face the problem of redesigning their lives dependent on their disability and thereafter according on their ability. This need for constant redesign persists throughout a SCl survivor's life as their disability and capability evolve and also as society's attitude changes. Therefore this presents another layer of complexity to the RSA challenge, in how to prepare SCl survivors to respond to this dynamic.

A central question for this programme of enquiry is one of the possibility of improved self-reliance and resourcefulness through autonomous designerly-like approaches and activities to the complex daily living challenges for SCl survivors. Can SCl survivors develop self-reliance and resourcefulness (i.e. designerly qualities) initially with the help of designers and, if so, can they autonomously practise designing and designerly approaches to 'wicked' problems of daily living, and if so at what point? Much 'inclusive design' has been concerned with 'participative', 'inclusive' and 'co-design' processes. In these, however, designers have been involved to a greater or lesser extent as catalysts and facilitators creating the conditions for designerly activities. 'Inclusive Design' has also had a role in the shift in attitude from the justification of any involvement at all of end users in the design process, through to that of the 'design partner' (Cassim, 2010) with the increasing recognition of the value of the lay or special user's contribution through facilitated design processes. Indeed, this idea has been further developed by some authors towards an understanding of design as a 'distributed social accomplishment' (Kimbell, 2009), e.g. where 'stakeholders are co-designers and designers are another kind of stakeholder'. However, in all these cases designers are present to a greater or lesser extent and the question remains whether $\mathrm{SCl}$ survivors could autonomously demonstrate designerly practice. In more recent work Kimbell (2011) gives useful pointers towards the 'embodied material practices' of design and asks if 'design is a special way of engaging with and acting on the world, unique to designers, or shared by others such as managers too'. If it is a special way of engaging with - or acting on - the world, but not unique to designers, can this be nurtured in SCl survivors - initially 
heightening awareness of one's innate capabilities through contact with designers, and then ultimately without the designer being part of the activity or process at some stage? As a designer one cannot be presumptuous about other's abilities: as an exemplar of how disabled people empower themselves the Needaloo.org (2012) website has been created for the geographical location of disabled toilets created by someone with a disability and is monitored by a large group of disabled people.

All this, then, provides useful pointers to the programme of further enquiry with QENSIU, to explore: 1) the inherent resourcefulness found within SCl survivors; 2) the conditions for enabling designerly approaches - as distinct from and to complement the current QENSIU approaches - to managing the 'wicked' problems of daily living for $\mathrm{SCl}$ survivors whether these conditions are to be created within or outside QENSIU; 3) the extent and duration of designers' involvement required with $\mathrm{SCl}$ survivors to determine the potential for SCl survivors' autonomous use of using design approaches in tackling some of the more practical problems of daily living; 4) the possibilities of a longitudinal study to look at the longer-term autonomous application of designerly skills and approaches by SCl survivors post-discharge; and most importantly, from the QENSIU perspective, 5) if these approaches have potential to address at least some of the post-discharge problems encountered by SCl survivors and referred to earlier.

\section{References}

Bate, P. and Robert, G. (2007) Bringing User Experience to Healthcare Improvement: The Concepts, Methods and Practices of Experience-Based Design. Oxford: Radcliffe Publishing.

Bury, M. R. (1982). 'Chronic illness as biographical disruption'. Sociology of Health and IIIness, 4: 167-182.

Campbell, E. (2009). You Know More Than You Think You Do: Design as Resourcefulness \& Self-Reliance. London: Royal Society of Arts.

Campbell, E. (2011). 'Design \& rehabilitation: A three-day workshop in design people with spinal cord injuries'. London: Royal Society of Arts. Available at: http://www.thersa.org/_data/assets/ pdf_file/0007/562642/Design-and-rehab.pdf [accessed 25 May 2012].

Cassim, J. (2010). 'Designing effective user interactions: Examples from the Challenge Workshops'. Proceedings of the $3^{\text {rd }}$ International Conference for Universal Design, Hamamatsu 2010, Japan. CD ROM ISBN 978-4-9903720-3-3.

Cottam, H. and Leadbeater, C. (2004). 'Health: Co-creating services'. London: The Design Council. Available at: http://www. designcouncil.org.uk/Documents/Documents/Publications/ RED\%20Paper\%2001_Design_Council.pdf [accessed 31 March 2012]. 
Department of Health (2005). Creating a Patient-led NHS: Delivering the NHS Improvement Plan. Available at: http://www.dh.gov.uk/ publications [accessed 25 January 2012].

Design Council (2008). 'Why encouraging NHS staff to think differently is good for the nation's health'. London: The Design Council. Available at from http://www.designcouncil.org.uk/Case-studies/ DCM-case-studies/NHS/ [accessed 25 January 2012].

Dickson, A. O'Brien, G., Ward, R., Flowers, P., Allan, D. and O'Carroll, R. E. (2011a). 'Adjustment and coping in spousal caregivers following a traumatic spinal cord injury: An interpretative phenomenological analysis'. Journal of Health Psychology, 17: 247-257.

Dickson, A., Ward, R., O'Brien, G., Allan, D. and O'Carroll, R. E. (2011b). 'Difficulties adjusting to post-discharge life following a spinal cord injury: An interpretative phenomenological analysis' Psychology, Health and Medicine, 16(4): 463-474.

Engine (2012). Available at: http://www.enginegroup.co.uk/service design/methods/ [accessed 31 March 2012].

IDEO (2009). 'Human centered design toolkit'. Available at: http:// www.hcdtoolkit.com [accessed 16 April 2010].

Kimbell, L. (2009). 'Beyond design thinking: Design-as-practice and designs-in-practice'. Available at: http://www.lucykimbell.com/ stuff/CRESC_Kimbell_v3.pdf [accessed 25 May 2012].

Kimbell, L. (2011), 'Rethinking design thinking: Part 1'. Design \& Culture, 3(3): 285-306.

Kimbell, R. and Miller, S. (1999). 'Design Skills for Work. Part 2 Fieldwork Report: Distinctive Skills and Implicit Practices. London: Goldsmiths, University of London.

Lawton, J. (2009), 'Illness, biography and narrative'. Sociology of Health \& IIIness (editorial, Virtual Special Issue). Available at: http://www.blackwellpublishing.com/shil_enhanced/virtual3_full. asp [accessed 25 May 2012].

Macdonald, A. S., Teal, G., Bamford, C. and Moynihan, P. J. (2012). 'Hospitalfoodie: An inter-professional case study of the redesign of the nutritional management and monitoring system for vulnerable older hospital patients'. Quality in Primary Care, 20(3): 169-177.

Meroni, A. and Sangiorgi, D. (2011). Design for Services. Farnham: Gower.

Needaloo (2012). Available at: (http://needaloo.org/ [accessed 5 June 2012].

Pickles, J., Hide, E. and Maher, L. (2008). 'Experience based design: A practical method of working with patients to redesign services'. Clinical Governance: An International Journal, 13: 51-58.

Stickdorn, M. and Schneider, J. (2010). This is Service Design Thinking: Basics, Tools, Cases. Amsterdam: BIS Publishers.

Tassi, R. (2009). 'Service design tools: Communication methods supporting design processes'. Available at: http://www. servicedesigntools.org/ [accessed 25 January 2012]. 
Thinkpublic (2012). Available at: http://www.thinkpublic.co.uk/ [accessed 31 March 2012].

Warren, L., Gott, M. and Hogan, S. (2012), 'Representing self, representing ageing: Look at me, images of women and ageing'. Sheffield: University of Sheffield. Available at: http:// www.newdynamics.group.shef.ac.uk/assets/files/NDA\%20 Findings_10.pdf [accessed 25 May 2012].

\section{Biography}

Professor Alastair Macdonald, a product designer by training, formerly Head of Department of Product Design Engineering at the Glasgow School of Art, is currently Senior Researcher in the School of Design. He deploys people-centred, co-design research methodologies within inter-professional healthcare teams, exploring the use of design approaches for healthcare service improvement and the design of innovative products. This work is funded by RCUK initiatives such as the AHRC/EPSRC's Designing for the $21^{\text {st }}$ Century, the cross-council New Dynamics of Ageing and the Medical Research Council's Lifelong Health and Wellbeing programmes.

\section{Address for Correspondence}

Alastair S. Macdonald, Senior Researcher School of Design, The Glasgow School of Art, 167 Renfrew Street, Glasgow G3 6RQ, UK. Email: a.macdonald@gsa.ac.uk

\section{Acknowledgements}

I would like to thank Emily Campbell and Melanie Andrews at the RSA; Mr David Allan, Dr Mariel Purcell and staff and patients at QENSIU; Prof Bernie Conway of University of Strathclyde; the Sylvia Adams Charitable Trust; Anne Taylor, Gemma Teal, Gayle Rice, Cara Broadley and Esme MacLeod at the Glasgow School of Art. 